\title{
NUEVOS ENFOQUES, DOGMAS, HEREJÍAS Y AJUSTES DE CUENTAS. UN MAPA APROXIMADO DEL PENSAMIENTO COMUNISTA ESPAÑOL EN EL EXILIO
}

\author{
NEW FOCUSES, DOGMAS, HERESIES AND RECKONINGS. AN \\ APPROXIMATE MAP OF SPANISH COMMUNIST THOUGHT IN EXILE \\ Juan Andrade* \\ Universidad de Extremadura (España)
}

\begin{abstract}
RESUMEN: Este artículo analiza varias líneas fundamentales del pensamiento político de los comunistas españoles durante el exilio de 1939 a 1975. Lo hace a partir de la consideración de las grandes obras publicadas, pero también de ensayos más livianos, de debates mantenidos en encuentros y órganos de dirección y de los mítines o discursos luego publicados en libros, revistas o folletos. En él se presta especial atención a las reflexiones teóricas acerca del Estado, las posibilidades de trasformación social y la tradición ideológica y cultural propia. También a los análisis históricos sobre el movimiento comunista, el PCE y su participación en la Guerra civil. De igual modo se atiende, muy especialmente, a los análisis acerca de la evolución del Franquismo y las posibles estrategias de transición a la democracia. La atención se centra en lo producido por aquellos militantes y dirigentes comunistas con mayores veleidades intelectuales y por aquellos intelectuales comunistas que tuvieron un mayor compromiso orgánico. Todo ello es abordado desde la perspectiva de la nueva historia del pensamiento político y la historia intelectual, que ponen el acento en cómo estas ideas se van tejiendo, más allá de su autoría individual, al calor de los conflictos sociales, políticos y culturales de una época.
\end{abstract}

PALABRAS CLAVE: exilio republicano, pensamiento político, Partido Comunista de España.

ABSTRACT: This article analyses several fundamental trends of the political thought of Spanish communists during the exile of 1939 to 1975 by considering great published works as well as lighter essays, debates held during conferences and in management bodies, and public meetings or conversations later published in books, magazines or pamphlets. Special attention is given to theoretical reflections on the State, the possibilities for social transformation, and ideological and cultural tradition. We also look at historical analyses of the communist movement, the PCE and its participation in the Civil War. Likewise, we examine analyses of the evolution of Francoism and possible strategies for transitioning to democracy, focusing on work produced by communist activists and leaders with greater intellectual flights of fancy and communist intellectuals with a greater commitment to the State. All of this is addressed from the perspective of the new history of political thought and the intellectual history which together stress how these become woven, beyond their individual authorship, into the core of the social, political and cultural conflicts of an age.

KEYWORDS: republican exile, political thought, Communist Party of Spain.

* Correspondencia a: Juan Andrade. Facultad de Formación del Profesorado, Universidad de Extremadura. Avda. de la Universidad, S/N. Cáceres 10.003 - jandradeb@unex.es - https://orcid.org/0000-0002-1953-1384.

Cómo citar: Andrade, Juan (2019). «Nuevos enfoques, dogmas, herejías y ajustes de cuentas. Un mapa aproximado del pensamiento comunista español en el exilio"; Historia Contemporánea, 60, 677-710. (https://doi.org/10.1387/hc.19519).

Recibido: 23 marzo, 2018; aceptado: 8 junio, 2018.

ISSN 1130-2402 - eISSN 2340-0277 / (C) 2019 UPV/EHU 
Hablar de «pensamiento político» supone referirse a un campo tan vasto como heteróclito difícilmente abarcable, incluso si lo acotamos, como es el caso, a una de sus tendencias contemporáneas, la del comunismo, y lo restringimos aún más a lo pensado por los comunistas españoles durante su exilio entre 1939 y 1975. De la amplitud del objeto de estudio se cobra enseguida conciencia si se repara en la cantidad de géneros y soportes en que ese pensamiento se ha manifestado: ensayo, historia, novela, teatro, poesía, conferencias, mítines, debates, etc. También si se repara en la variedad de significados que cabe atribuir a «lo político», un concepto tan polisémico que va de todo lo relativo a la vida pública, a decir de Aristóteles, a lo que sucede en el ámbito personal, según, por ejemplo, el feminismo de la segunda ola ${ }^{1}$.

A fin de acotar tan amplio campo y poner el foco en algunas dinámicas intelectuales concretas, en este artículo se analizan sobre todo aquellas reflexiones que conscientemente tuvieron que ver con el hecho político en sentido estricto, aquellas orientadas a ponderar la experiencia histórica del movimiento comunista y aquellas otras concebidas para justificar o reprobar la línea política del PCE en aquellos años. Ello incluye las reflexiones de los comunistas españoles sobre el Estado y las manifestaciones múltiples del poder; sus teorizaciones acerca de lo que en el argot de esta tradición serían las nuevas formas de explotación, dominación y alienación; los debates que mantuvieron en torno a las posibilidades de transformación revolucionaria de la sociedad, la conquista del poder o la reforma de los sistemas políticos; así como las consideraciones que hicieron sobre corrientes de pensamiento propias y ajenas. También se incluyen los análisis y debates sobre la evolución del movimiento comunista en general, del español en particular y, especialmente, del papel del PCE durante la Guerra Civil. De igual modo este artículo aborda los análisis de los comunistas españoles en el exilio sobre la evolución del régimen de Franco y sus propuestas de intervención política para España: sus líneas estratégicas, las modulaciones tácticas, las políticas de alianzas, los debates en torno a la reconciliación nacional o sus propuestas cambiantes de transición a la democracia.

Para acercarnos al pensamiento comunista del exilio se ha prestado especial atención a las obras más amplias y teóricamente fundamentadas;

\footnotetext{
${ }^{1}$ La concepción de lo político en Aristóteles, 1999. Sobre la idea de «Lo personal es político», Carol Hanisch, 1969.
} 
pero también a ensayos más livianos. De igual modo se han considerado discursos en mítines, materiales de comisiones de trabajo e intervenciones en órganos de dirección, que o bien fueron compilados en archivos o bien publicados en folletos, prensa, revistas teóricas y antologías del partido. Estos últimos formatos resultan particularmente interesantes porque fueron, con frecuencia, los materiales que circularon entre los cuadros y militantes de base del partido, que en absoluto constituyeron una masa pasivamente receptora de aquellas ideas, sino una comunidad política intelectualmente activa cuyas intervenciones, correcciones, resistencias y beneplácitos fueron modelando esas ideas, al tiempo que eran sistematizadas por algunas personas concretas.

¿Qué personas fueron estas a las que prestaremos especial atención? De un lado los dirigentes y cuadros del PCE en el exilio que por su capacidad, vocación o puesto de responsabilidad se sintieron llamados a escribir textos y ensayos sobre las cuestiones arriba citadas. Por otro, los intelectuales, académicos o ensayistas profesionales que mantuvieron en algún momento algún compromiso orgánico con el partido. En definitiva, aquí se analizan preferentemente los textos e intervenciones de políticos con veleidades intelectuales y de intelectuales con fuerte compromiso político.

El artículo pretende huir, pese al peso de su inercia, de la historia tradicional de las ideas políticas. Este enfoque presupone que estas ideas se elaboran en la mente portentosa de algunos intelectuales, condicionados, si acaso, por un mundo externo y envolvente al cual se suele aludir de manera genérica con el nombre de contexto. Según este esquema, estas ideas se remodelarían en el diálogo, más o menos horizontal, con las ideas elaboradas por otros autores del mismo nivel, para finalmente ser asimiladas, de forma vertical por aquellos que no estarían a idéntica altura, previa simplificación o degradación. Cuando desde este enfoque tradicional se habla de la influencia del pensamiento político, la cuestión suele reducirse a cómo las ideas se materializa, atendiendo a su grado de adhesión social, en concreciones más o menos fidedignas.

Frente a esta concepción aquí se apuesta por otra más compleja y actualizada, inspirada, entre otras, en la tradición gramsciana y en tendencias abiertas por la historia del pensamiento político de Cambridge, la historia de los conceptos promovida por Koselleck o la historia de los intelectuales inspirada en Pierre Bourdieu². El propósito es ver cómo es-

2 Gramsci, 2004; Skinner, 2002; Koselleck, 2012 y Bourdieu, 2012. 
tas líneas de pensamiento comunista en el exilio se fueron tejiendo y destejiendo al calor de los conflictos políticos, sociales y culturales de su tiempo y cómo eso que llamamos contexto no fue un éter envolvente, sino el espacio central de una producción discursiva en la que ese contexto quedó impreso. De igual modo aquí no solo se aborda el pensamiento político comunista atendiendo a su capacidad para orientar, prefigurar, inspirar, legitimar o racionalizar la acción política del PCE, sino que se considera en sí mismo como una «acción que incita a una acción» ${ }^{3}$.

El propósito de este artículo es, por tanto, analizar líneas de pensamiento comunista al calor de la experiencia convulsa, vertiginosa, variable y contradictoria de los comunistas españoles en el exilio. Para tomar conciencia de semejante experiencia basta citar una serie de acontecimientos y procesos que luego se tendrán en cuenta: derrota en la Guerra Civil, dispersión en el exilio, Pacto Molotov-Ribentrop, participación en la Segunda Guerra Mundial, relaciones problemáticas con los otros partidos del exilio, peso determinante de la Guerra Fría, dependencia de Moscú, crisis sesentaiochista, diseño y dirección de la lucha clandestina en el interior, etc. El propósito es analizar también esas líneas de pensamiento atendiendo a la tradición intelectual previa del comunismo español (pobre en origen pero enriquecida en el exilio), a la evolución general del pensamiento comunista de la época (con el peso de las versiones canónicas de las URSS y el empuje de las nuevas tendencias intelectuales del marxismo occidental) y a formas ritualizadas y corporativas de reflexión. La intención es hacerlo considerando el marco de las furibundas luchas de poder en el seno del partido y, en la medida de los posible, las diferentes trayectorias formativas, militantes y vitales de quienes hablaron y escribieron en cada momento.

\section{La Guerra Civil y la reconciliación nacional}

El PCE creció de manera exponencial durante la Guerra Civil gracias a su capacidad organizativa y propagandística a la hora de galvanizar el esfuerzo bélico, al prestigio y las posiciones de poder derivados del apoyo de la URSS a la República y gracias, también, a una orientación política centrada en la defensa del marco legal republicano como condi-

3 Jaume, 2004, pp. 118-120. 
ción previa para avanzar más tarde hacia el horizonte revolucionario que el estallido de la guerra había despejado en el imaginario de buena parte de la clase obrera. Si algo caracterizó al PCE durante la Guerra fue el sostenimiento de estas posiciones, con evidentes modulaciones, durante toda la contienda, lo que le llevó a enfrentarse, al principio, con quienes consideraban que había llegado la hora de la revolución proletaria y, al final, con quienes consideraban que ya no tenía sentido seguir resistiendo militarmente ${ }^{4}$.

Como en el caso de las otras grandes familias ideológicas de la República los dirigentes y militantes comunistas de mayor formación intelectual escribieron sobre la Guerra Civil. A lo largo de la década de los sesenta la dirección del PCE se propuso además la hercúlea tarea de historiar la guerra para dar cumplida cuenta del papel jugado por el partido. Con ello se pretendía contrarrestar la influencia creciente de la literatura anticomunista sobre la Guerra Civil y activar a la militancia, sobre todo del exilio, en torno aquella «gesta heroica». El proyecto concluyó con la publicación en 1967 de la obra Guerra y Revolución en España 1936-39, seis volúmenes en los que se fijaría la visión oficial del partido. Según el PCE, aquella había sido una guerra revolucionaria contra los resabios feudales y oligárquicos de la sociedad española, una guerra por la soberanía nacional frente a la invasión extranjera de alemanes e italianos, una guerra de dimensiones internacionales contra la expansión del fascismo y una guerra por la defensa de un régimen democrático y social, el de la II República, que una vez salvaguardado en sus límites e integridad permitiría retomar el camino a destinos socialistas más ambiciosos. Según esta obra, el papel del partido en la contienda había sido ejemplar, porque había sabido identificar desde primera hora la verdadera naturaleza del conflicto, había conectado con los sectores más aguerridos en la defensa de la República, había defendido la política unitaria del Frente Popular, había sostenido la resistencia hasta el final y había desarrollado los dos instrumentos más eficaces para ello: el Comisariado y el Ejército Popular. Las causas de la derrota había que buscarlas, en opinión del partido, en el aislamiento del que fue objeto la República por parte de las potencias extrajeras, sobre todo de Francia e Inglaterra, a excepción, por supuesto, de la URSS.

Para la elaboración de esta obra magna fue necesario poner a trabajar a buena parte del aparato del PCE y a las organizaciones territoriales

\footnotetext{
${ }^{4}$ Hernández Sánchez, 2010.
} 
del exilio en la búsqueda documental y en la recuperación de los testimonios de los protagonistas del partido en la contienda. La obra contó con la experiencia previa de la elaboración de una síntesis sobre la historia general del partido, Historia del Partido Comunista de España, publicada en 1960, a partir del trabajo de la misma comisión, formada por Dolores Ibárruri, Manuel Azcárate, Luis Balaguer, Antonio Cordón, Irene Falcón y José Sandoval, algunos de los dirigentes de mayor nivel intelectual del partido.

En una línea concomitante se elaboraron también trabajos, bien a instancias de la dirección del partido, bien motu proprio, orientados a justificar la política exterior soviética, no solo en lo tocante a la Guerra Civil española, sino en lo referente a su polémico papel en vísperas de la Segunda Guerra Mundial con la firma del Pacto Molotov-Ribbentrop. Con este propósito publicó Margarita Nelken en 1943 su ensayo Las Torres del Kremlin. La obra venía precedida de un prólogo que era una verdadera oda a Stalin. En él hacía suyas las famosas palabras con que Henri Barbusse lo describió años antes: «ese hombre que tiene cabeza de sabio, rostro de obrero y ropa de soldado» $»^{5}$. Cabe recordar que en los momentos en que Margarita Nelken reproducía esas líneas su hijo, al que dedicaba el libro, combatía contra el nazismo en las filas del Ejército Rojo, donde al poco tiempo terminaría perdiendo la vida.

Más allá de la Guerra Civil y la Segunda Guerra Mundial los comunistas también escribieron su propia historia del movimiento obrero, incluyendo aquella de la que se sentían parte pese a haber acontecido con anterioridad a la configuración orgánica del movimiento comunista. Es el caso, por ejemplo, de los trabajos del antiguo dirigente y sindicalista socialista Amaro del Rosal, Los congresos obreros internacionales en el siglo XIX, publicado en 1958 y Los congresos obreros internacionales en el siglo XX: de 1900 a 1950, publicado en 1963. También de los trabajos de Rito Esteban Novillo, Sobre el movimiento obrero de Europa y América y Lucha de clases y movimiento obrero, publicados respectivamente en 1946 y $1961^{6}$.

Los primeros años del exilio fueron particularmente duros para el PCE. Había salido derrotado de una guerra civil de más de tres años, estaba enfrentado a buena parte de los partidos del extinto Frente Popular,

\footnotetext{
5 Nelken, 1943, p. 34.

${ }^{6}$ Del Rosal, 1958 y 1963. Esteban Novillo, 1946 y 1961
} 
había sido atravesado por la contradicción del Pacto Molotov-Ribentrop, había combatido después de forma tenaz en varios frentes de la Segunda Guerra Mundial, sufrió entonces la muerte de su Secretario General José Díaz, estaba disperso y asfixiado en el exilio, andaba bajo la dependencia coactiva de la URSS y en el interior era ferozmente perseguido por la dictadura de Franco. En ese terrible contexto de resistencia, tensión y celo tuvieron lugar los procesos de depuración de destacados disidentes o de quienes cayeron en desgracia ante la dirección por su voluntad de poder, su prestigio o las sospechas (con frecuencia poco fundadas) de traición. Entre los casos más sonados destacan los de Jesús Hernández, Enrique Castro, Jesús Monzón o Joan Comorera, a los que habría que sumar las decenas de cuadros apartados o sentenciados a muerte.

Estos procesos se vieron azuzados además por el cambio que en aquellos años se fue produciendo en la distribución interna de poder, que del grupo de dirigentes emblemáticos de la Guerra Civil, como Pasionaria, Juan Modesto o Vicente Uribe, fue basculando al de los jóvenes procedentes de la JSU, nucleados en torno al tándem formado por Santiago Carrillo y Fernando Claudín. Con algunos de esos métodos tan abrasivos y con otros más seductores Carrillo logró llegar a la cúspide del partido en el Comité Central ampliado de 1956, donde fue investido Secretario General de facto, y en el VI Congreso celebrado en Praga entre diciembre de 1959 y enero de 1960, donde lo fue ya de iure. Para ello resultó determinante el apoyo que recibió de Dolores Ibárruri y, más aún, de Moscú, obtenido gracias, entre otras cosas, a su capacidad a la hora de presentarse como valedor dentro del PCE del proceso de renovación limitada que Nikita Kruschev abrió en el XX Congreso del PCUS de 19567.

La adhesión temprana y ostensible de Carrillo y Claudín al giro que abre el XX Congreso del PCUS contribuyó a mitigar en el caso del primero y a neutralizar en el caso del segundo la responsabilidad de ambos en la estalinización del PCE; pues, sin menoscabo de los rasgos adquiridos en la República y la Guerra Civil, y pese a los intentos de Carrillo y Claudín de descargar a última hora sobre las espaldas de los viejos dirigentes esa responsabilidad, lo cierto es que el estalinismo, como cultura política y modelo de funcionamiento interno, cuaja sobre todo en el PCE de los años cuarenta y cincuenta que ellos controlaron en mayor medida ${ }^{8}$.

7 Service, 2015, pp. 338-344.

8 Hernández Sánchez, 2015, p. 330. 
Estas prácticas punitivas, de estigmatización, degradación, expulsión o aplicación de la pena capital en el hermético marco de la justicia interna del partido, así como los desplazamientos más pacíficos del núcleo de poder que sufrieron quienes perdieron el pulso con la joven guardia, inspiraron una amplísima literatura de corte ensayístico y muchas veces autobiográfico de distinta naturaleza y motivación. Esta producción se alimentó a su vez de la evolución ideológica de sus autores, generalmente en un sentido contrario al del mundo del comunismo y, especialmente, al de su referente estatal, la URSS. Buena parte de esta «literatura del desengaño» fue estimulada por las tentadoras ofertas o ayudas que algunos de sus autores recibieron de estancias culturales financiadas por la CIA o el Régimen de Franco ${ }^{9}$. El resultado fue la difusión de una perspectiva virulenta e histriónicamente anticomunista fundamentada en una experiencia autobiográfica a veces cierta, otras exagerada y en ocasiones directamente inventada. Entre quienes abjuraron completamente de la URSS y de la causa del comunismo, recibiendo por ello el amparo de sus viejos enemigos, están, por ejemplo, Valentín González «El Campesino» o Enrique Castro Delgado. El primero, figura militar más que controvertida en la Guerra Civil, recibió el respaldo, de la mano de Julián Gorkin, del Congreso para la Libertad de la Cultura y terminó publicando libros de amplia y bien financiada difusión. No en vano se especula con que fuera Julián Gorkin quien redactara sus libros Vida y muerte en la URSS y Comunista en España y antiestalinista en la URSS ${ }^{10}$, habida cuenta de las limitaciones formativas de su autor nominal, rayanas en el analfabetismo. Enrique Castro Delgado, sin embargo, había colaborado en Mundo Obrero y otros órganos de expresión vinculados al PCE, lo que sí hace presuponer que los libros escritos en el exilio fueran realmente de su autoría. Nos referimos a La vida interna de la Komintern: Cómo perdí la fe en Moscú y a Hombres made in Moscú, publicados en 1950 y 1963 respectivamente ${ }^{11}$.

Caso distinto es el de Jesús Hernández. Dirigente a temprana edad del PCE y Ministro de Instrucción Pública durante buena parte de la Guerra Civil, rivalizó con Dolores Ibárruri por el control del partido a la muerte de José Díaz. De tal pulso salió al final derrotado, denigrado y expulsado, para abrazar posteriormente la vía heterodoxa propuesta por Tito desde Yugoslavia, lo que le permitió a encontrar trabajo en la embajada de este

\footnotetext{
9 Sobre el papel del Congreso por la Libertad de la Cultura: Glondys, 2012.

${ }_{10}$ González, 1951 y 1952, respectivamente.

11 Castro Delgado, 1950 y 1963.
} 
país en México ${ }^{12}$. Desde esa posición, y al margen en gran medida de los circuitos anticomunistas financiado por el Congreso para la Libertad de la Cultura, escribió un famoso descargo anti estalinista, Yo fui ministro de $\operatorname{Stalin}^{13}$, en clave autobiográfica y cierto tono sensacionalista a la vez que resentido, en el que, por otra parte, reafirmaba su compromiso con la causa primigenia del socialismo.

El afianzamiento del poder del grupo de Carrillo condujo a la aprobación de una nueva línea política, tipificada en la «Declaración del PCE por la reconciliación nacional. Por una solución democrática y pacífica del problema español» de 1956. Según lo declarado en el texto, la Guerra Civil había dejado de ser la línea fundamental de demarcación de las tensiones en España, toda vez que el franquismo golpeaba igualmente a los sectores populares que habían combatido a un lado $u$ otro en la contienda y excluía del Gobierno a muchos de quienes le había dado apoyo: «el Partido Comunista de España declara solemnemente estar dispuesto a contribuir sin reservas a la reconciliación nacional de los españoles, a terminar con la división abierta por la guerra civil y mantenida por el general Franco» ${ }^{14}$. Para el PCE eso ofrecía la oportunidad de construir una nueva mayoría antifranquista con aquellos que, habiendo apoyado el golpe, empezaban a desmarcarse o a disentir de la dictadura. Al respecto se ponían los casos concretos de Calvo Serer, Pedro Laín y Dionisio Ridruejo. Esa vía pacífica se vería favorecida por una cierta distensión en las relaciones entre los bloques de la Guerra Fría, que el PCE subrayaba, o más bien exageraba, en sintonía con el nuevo lenguaje de la era Kruschev. La finalidad de todo ello era ir de manera estrictamente pacífica hacia un sistema político democrático en España que garantizara a su vez un periodo de reconciliación y paz definitivo entre todos los españoles:

España se encuentra ante una coyuntura en la que si las fuerzas de derecha y de izquierda tienen en cuenta la dura y terrible lección de la guerra y de la etapa fascista, es posible poner fin a un largo período histórico de pronunciamientos, guerras civiles e intervenciones extranjeras, e inaugurar una nueva era de paz civil ${ }^{15}$.

12 Véase la biografía de Jesús Hernández escrita por Hernández Sánchez, 2007.

13 Hérnandez Tomás, 1953.

14 «Declaración del PCE por la reconciliación nacional. Por una solución democrática y pacífica del problema español», junio 1956, Carpeta 73, Sección Documentos, Archivo Histórico del PCE.

15 Ibidem. 
La «Declaración del PCE por la reconciliación nacional», que supuso un giro importante en la historia del PCE, no deja de ser un documento de su tiempo, lanzado públicamente para romper el aislamiento al que estaba sometido el partido y con unos contenidos concretos muy atados a aquella coyuntura de $1956^{16}$. En la transición, sin embargo, la noción de reconciliación nacional fue resignificada para justificar el acuerdo no ya con los disidentes previos de la dictadura, como decía el documento, sino con los herederos de la misma que nunca llegaron a abjurar de ella. Luego incluso se ha leído, de manera muy presentista, como la prefiguración por parte del PCE del modelo de transición a la democracia de la segunda mitad de los setenta, que en muchos sentidos entró en contradicción con lo que el partido fue planteando en los años sesenta y principios de los setenta. Véase por ejemplo el Pacto para la libertad de 1972 o el Manifiesto-Programa de 1974, donde la propuesta del partido era una clara ruptura democrática con la dictadura gestionada por un gobierno provisional de amplia representación donde cupieran, efectivamente, aquellos sectores desgajados de la dictadura. Por otra parte, también se ha hecho, desde esta visión presentista, una lectura parcial de la literalidad de la declaración, donde ciertamente se habla del no ajuste de cuentas con el bando sublevado, pero donde la reconciliación también se condicionaba a la «reparación» del sufrimiento causado:

El Partido Comunista considera que una verdadera amnistía, que permitiera el regreso de los exilados, sin discriminación ni vejaciones; la liberación de los presos políticos; la reconstrucción de decenas de miles de hogares deshechos y la reparación de las injusticias cometidas, allanaría el camino al entendimiento y crearía el terreno apropiado a la convivencia nacional, dando a los españoles las posibilidades de vivir libres del temor a la persecución y a la venganza. El Partido Comunista considera que sobre esta base puede cancelarse el pasado $^{17}$.

En cualquier caso la Política de Reconciliación Nacional de 1956 supuso un cambio importante en el PCE porque ponía definitivamente fin a la lucha armada y apostaba por utilizar los resquicios legales del régimen

16 Sobre el significado originario de la Política de Reconciliación Nacional: Erice, 2006 y Valverde 2006.

17 «Declaración del PCE por la reconciliación nacional. Por una solución democrática y pacífica del problema español», doc. cit. 
para generar una oposición pacífica de masas, lo que tan buenos resultados le daría posteriormente al partido. También porque profundizaba en el compromiso con las libertades públicas, los valores democrático-parlamentarios y el pluralismo político, por los que el PCE ya venía apostando al menos desde la Guerra Civil, aunque hasta entonces de manera muchas veces matizada, concibiéndolos en cierto sentido como instrumentos circunstanciales a través de los cuales se debería ir luego hacia un sistema basado en otros valores y asentado en otra institucionalidad. Con la Política de Reconciliación Nacional se dio un impulso a esta evolución de largo recorrido orientada a la reconciliación definitiva con las formas y valores políticos con frecuencia llamados liberales, pero que más ajustadamente cabría considerar republicanos en rigor histórico ${ }^{18}$.

\section{Herejía y conversión. La crisis de 1964 y las trayectorias intelectuales de Fernando Claudín y Jorge Semprúm}

En 1964 tuvo lugar el debate estratégico más importante del PCE en el exilio, que entrañó una profunda crisis en su núcleo dirigente. La crisis arrancó de una enmienda a la totalidad por parte de Fernando Claudín a los análisis y tesis oficiales del PCE, lo que fue interpretado (porque también era esta su intención) como un cuestionamiento de la autoridad de su viejo amigo Santiago Carrillo. Por una cosa y otra la pugna se libró con tal dureza que terminó con la expulsión de Fernando Claudín y Jorge Semprún en 1965 y con la salida, voluntaria o forzada, de los dirigentes y cuadros que los respaldaron ${ }^{19}$.

Claudín expuso sus tesis en el discurso pronunciado en la reunión del Comité Ejecutivo del PCE el 27 de marzo de 1964. La dirección le respondió oficialmente por medio de una «Declaración del Partido Comunista de España de junio de 1964» y de un amplio texto publicado en el número 38 de Nuestra Bandera, que firmó Santiago Carrillo con el título de «¿Liberalización o democracia?» ${ }^{20}$ A estos textos Fernando Claudín respondió con otro titulado «Las divergencias en el partido». En 1978 todos estos escritos fueron publicados por Fernando Claudín en la editorial 2013.

${ }_{18}$ Sobre el significado aquí manejado de republicanismo: Doménech, 2004 y Duarte,

19 Molinero e Ysás, 2017, pp. 34-36.

${ }^{20}$ Carrillo, 1964. 
Viejo Topo con el título Documentos de una divergencia Comunista ${ }^{21}$. El libro, que entonces tuvo una amplia difusión, constituye un buen ejemplo del lugar importante que algunos debates del exilio tuvieron en la transición, así como del amplio reconocimiento político y cultural que merecieron en la nueva democracia algunos de los análisis y, sobre todo, de las posiciones políticas que se plantearon entonces.

A la altura de 1964 la propuesta oficial del PCE consistía en enlazar la crisis que intuía inminente de la dictadura con lo que entonces llamaba «la democracia antifeudal y antimonopolista». Se trataba de una etapa donde, al tiempo que se realizarían las tareas pendientes de la revolución burguesa en España, se acometerían importantes transformaciones democráticas con fuertes contenidos sociales, que a medio plazo se podrían enlazar, a su vez, con una fase ya sí socialista. El arranque de la secuencia requeriría de una acción pacífica de masas que colapsaría la dictadura y que indistintamente recibió el nombre de Huelga Nacional Política o Huelga Nacional Pacífica.

La tesis de Claudín negaba la mayor. En su opinión el modelo de crecimiento económico impulsado por la dictadura, en un contexto internacional de estabilidad y tolerancia hacia el régimen, no hacía prever ninguna crisis social en España, si acaso una crisis de la forma fascista del Estado. Claudín planteaba que al llegar esta situación la propia oligarquía española buscaría una salida a la dictadura en el marco de un régimen más o menos democrático, donde se preservarían los intereses del capital monopolista. En esas circunstancias, ni la clase obrera, realmente en aumento, ni el movimiento obrero en auge, que hegemonizaba el PCE, podrían forzar y dirigir un proceso de cambio político y menos aún vincularlo a una nueva etapa de transformaciones sociales. El partido debía, por tanto, rebajar sus aspiraciones y acumular fuerzas para, llegado el momento, acelerar e intensificar el proceso de reformas democráticas abierto por los sectores más audaces del régimen, por medio de una conjunción de presiones y negociaciones. Luego ya, tras una etapa de maduración del movimiento obrero facilitada por el nuevo contexto de libertades, cabría plantearse el salto hacia otra etapa más ambiciosa de fuertes contenidos sociales.

El debate en el exilio entre Santiago Carrillo y Fernando Claudín despertó el interés de políticos e intelectuales en la transición y la democra-

21 Claudín, 1978. 
cia, quienes en la mayor parte de los casos vinieron a constatar tres cosas ciertas. Por una parte, que los análisis de Claudín eran muchísimo más rigurosos y fundamentados y se ajustaban más a las circunstancias de la España de la época. Por otra, que el desarrollo de la transición en la segunda mitad de los setenta encajó mucho mejor en sus previsiones. Y, finalmente, que la política seguida por Carrillo durante la transición se terminó pareciendo mucho a la defendida por Claudín diez años antes, cuando fue expulsado por ello.

No obstante, buena parte de la estima intelectual y política de la que ha disfrutado Claudín en la España postransicional se debe a la imagen que de él se ha construido como icono de un supuesto sentido común prefigurador, desde primera hora, de los límites razonables de la transición, tanto más ensalzado en la medida que procedía de una tradición, como la comunista, tan dada a salirse de ellos. Así, la consideración positiva de los pronósticos de Claudín acerca de la transición parece confundirse a veces con la celebración de sus resultados. Así, la racionalización de los límites del proceso, anticipados en cierta medida por Claudín, ha servido al empeño de presentar como regresivos o quiméricos los proyectos que trataron de desbordarlos, y que fueron, por otra parte, los que inspiraron a la mayoría de quienes lucharon contra la dictadura, a quienes en última instancia lograron ampliar precisamente esos límites. Por otra parte, insistir demasiado en el carácter anticipador de los pronósticos de Claudín acerca de un proceso, el de la transición, que terminó desarrollándose más de diez años después de que estos pronósticos fueran esbozados, sugiere que el proceso estuviera predeterminado desde entonces y que ninguna contingencia posterior hubiera podido variar el curso supuestamente necesario de los acontecimientos. Algo de esto sugirió Santiago Carrillo al plantear, con razón, aunque pro domo sua, que tampoco en 1964 parecían darse las condiciones para que, apenas diez años después, se abriera en Portugal el proceso revolucionario que, por otra parte, él tanto desprecióo 22 . Otra de las razones del reconocimiento que merecieron las tesis de Claudín se debe a las posiciones de poder político y cultural que ocuparon en la democracia quienes entonces las defendieron en la clandestinidad y en el exilio. Jorge Semprún terminó siendo Ministro de Educación del Gobierno de Felipe González, Javier Pradera editorialista de El País y el propio Claudín editor de Siglo XXI y director de la Fundación Pablo Iglesias del PSOE.

${ }^{22}$ Carrillo, 1983, p. 90. 
Sin perjuicio de su considerable rigor y adecuación a las circunstancias de la época, las tesis de Claudín reproducían en gran medida el mecanicismo y el etapismo tan característico del marxismo-leninismo de aquella época de estabilización de los bloques de la Guerra Fría y estancamiento de las perspectivas de cambio $^{23}$. Por una parte, denotaban una consideración de los procesos de cambio muy de la época, que los entendía como resultado de grandes dinámicas económicas objetivas a las que supeditar la práctica política. Por otra, al igual que las de Carrillo, las tesis de Claudín bebían de la vieja concepción teleológica de llegada al socialismo por la vía del enlace de etapas consecutivas orientadas a ese fin. La diferencia radicaba en que Claudín situaba este fin más lejos al proponer una etapa intermedia más. Finalmente, las tesis de Claudín parecían confundir el pronóstico nada halagüeño que ofrecían los análisis del momento con el programa más ambicioso de cambio que se supone debía impulsar un partido comunista, negando la posibilidad de que la lucha por ese programa pudiera modificar el escenario esbozado por el pronóstico.

A partir de la crisis del 64 Fernando Claudín desarrolló una importante trayectoria intelectual en el exilio. La expulsión del PCE le permitió dedicarse más tranquilamente al estudio y le permitió hacerlo liberado ya de la lacerante disciplina de un partido que, a diferencia por ejemplo del Partido Comunista Italiano, no tenía mucho nervio intelectual. La expulsión de Claudín del PCE implicó su ruptura, no solo militante, sino intelectual, ideológica y personal, con el mundo comunista, al que había consagrado la mayor parte de su vida. Pese a ello, Claudín siguió pensado durante buena parte de sus años en el exilio dentro del horizonte políticocultural de la trasformación socialista de la realidad. Más allá de las convicciones propias, a esa persistencia contribuyeron probablemente dos hechos. Por un lado, la necesidad de sacudirse el estigma de disidente derechista que recibió de su anterior partido. Y, por otra parte, la revigorización general de las expectativas revolucionarias alrededor de la fecha simbólica de 1968 y de la proliferación de las heterodoxias que constituyeron el campo de la llamada Nueva Izquierda. Este nuevo contexto entrañó temporalmente un giro generalizado de la izquierda hacia la izquierda, tanto más acusado en aquellas organizaciones e intelectuales en principio situadas a la derecha de los partidos comunistas. El giro vino por contagio

${ }^{23}$ Sobre las tendencias intelectuales del marxismo occidental en esta época Anderson, 2015, pp. 59-63. 
ambiental o por la necesidad de competir con los partidos comunistas en los países donde eran más influyentes (Italia, Francia, España, Portugal, Grecia, etc. $)^{24}$.

Ambas cosas, defensa de la expectativa de transformación socialista de la realidad y ruptura dramática con el movimiento comunista, debieron contribuir a reforzar la tesis central de la que es su mejor obra, Crisis del movimiento comunista, publicada en el exilio en 1970. Según Claudín, el movimiento comunista estaba sumido desde los años 50 en una crisis irreversible derivaba de los orígenes mismos de la URSS, de la forma en que se expandió la Komintern y de la inercia brutal del estalinismo:

En el curso de la investigación emprendida llegué a una conclusión que inicialmente no era evidente para mí: el movimiento comunista - el partido estaliniano, tanto en sus dimensiones nacionales como internacionales, lo mismo en el ejercicio del poder que como instrumento de lucha por el poder- había entrado en los años cincuenta en una crisis general, irreversible. Y por su propia naturaleza no tiene posibilidades de autotransformarse, de «negarse» en el sentido hegeliano ${ }^{25}$.

Lo mejor de Crisis del movimiento comunista radica en la arqueología que hace Claudín de las ideas y de las prácticas fundacionales del movimiento comunista, la explicación que ofrece del proceso de solidificación institucional de las políticas de excepción de la Guerra Civil rusa y el relato de cómo estas ideas y prácticas se trasfirieron con la ramificación por toda Europa de la Internacional Comunista. Lo peor es que Claudín atribuye la mayor parte del desarrollo del movimiento comunista al férreo control de la URSS, especialmente, a la celosa intervención de un Stalin que a veces deviene en el Deus ex machina de su relato. En opinión de Fernando Claudín, la teoría del «socialismo en un solo país» condujo «a identificar absolutamente la seguridad del Estado soviético con los intereses supremos de la revolución mundial, y por tanto a supeditar los intereses del movimiento en cada país a la razón de estado de la Unión soviética» ${ }^{26}$. Aunque es verdad que el control de Stalin sobre el movimiento comunista fue extraordinario y su voluntad de poder desmedida,

\footnotetext{
24 Andrade, 2015, pp. 140-155.

25 Claudín, 1970, p. XVIII

${ }^{26}$ Claudín, 1970, p. 86
} 
aunque también es cierto que los intereses de Estado de la URSS se impusieron normalmente a los intereses de cualquier partido comunista o al futuro incluso de cualquier revolución social, la explicaciones de Claudín derivan a veces en una suerte de teoría conspirativa que infravalora la complejidad de los procesos que analiza y de la autonomía, aunque fuera relativa, que a distintas escalas y en diferentes momentos el movimiento comunista tuvo en muchos países ${ }^{27}$. El tótem de Stalin que Claudín había idolatrado hasta 1956 atraviesa su obra como un espectro siniestro cuya sombra omniabarcante enturbia la visión de procesos históricos caracterizados por una complejidad que en muchos momentos del libro Claudín refleja, contradictoriamente, de manera magistral.

Lo mejor de este libro de Claudín es su amplia perspectiva temporal y geográfica, la profusa información aportada, la profundidad conceptual, el hilvanado de datos y conceptos, su sólida arquitectura o la densidad del aparato crítico, con infinidad de notas al final del libro y remisión a obras y documentos. Lo peor, la sujeción automatizada a algunos de los esquema rígidos del marxismo-leninismo esclerotizado que critica, su tono categórico y muchas veces hiperbólico, la limitaciones a la hora de tomarse en serio a quienes desprecia, simplificándolos o parodiándolos. El libro, en definitiva, se mueve constante y contradictoriamente entre análisis profundos, lúcidos y fundamentados y consideraciones apresuradas procedentes de la propia experiencia biográfica, una experiencia que aflora traumática y necesitada con frecuencia de reelaboración a posteriori. Da la sensación, en definitiva, de tratarse de un libro escrito por una mente lúcida, pero desde una herida abierta.

Jorge Semprún experimentó una evolución ideológica paralela a la de su compañero y amigo Fernando Claudín. Su pensamiento político, sin embargo, se expresó sobre todo en su rica obra literaria, construida a golpe de estilo, reflexión intelectual y memoria personal. Jorge Semprún Maura estuvo a caballo entre la primera y la segunda generación del exilio, a donde partió con su padre, el diplomático e intelectual republicano José María Semprún Gurrea. En 1942 se afilió al PCE y al poco tiempo fue detenido como miembro de la resistencia antinazi e internado en el campo de concentración y exterminio de Buchenwald, del que logró sobrevivir gracias a la red de la organización comunista en el campo, a las tareas que pudo desempeñar en función de su cualificación y a la suerte

27 Sobre esta relativa autonomía véase por ejemplo Wolikov, 2016. 
que acompañó a pocos de los que pasaron por esa experiencia dantesca. Tras ser liberado se incorporó de lleno a la lucha clandestina del PCE en el interior de España, entre otras razones, como él mismo explica, para no volver la vista a la terrible experiencia del campo. Tras la crisis de 1964, en la que defendió activamente las tesis de Claudín, que eran también las suyas, rompió radicalmente con la tradición comunista surgida de la III Internacional y, con el paso del tiempo, con la tradición socialista revolucionaria en general. A partir de esa fecha desarrolló una importante carrera literaria e intelectual, que se concretó en varios libros y guiones cinematográficos ${ }^{28}$.

La originalidad de la obra de Semprún radica, entre otras cosas, en su triple condición de testigo, protagonista y cronista de la historia. Está escrita mediante el complejo y nunca lineal ensamblaje de los retazos de su memoria, con esmero literario y muchos de los recursos formales de la ficción. No es estrictamente una obra autobiográfica, pues el relato de sus vivencias, la introspección personal o el diálogo consigo mismo están entrelazadas con la historia, de la que pretende dar cuenta y sobre la que pretende intervenir, y porque en el relato van sobreviniendo análisis políticos y reflexiones personales e ideológicas. Su obra incluye tangencialmente un sinfín de temas, pero gira sobre todo en torno a dos, su experiencia en el Campo Buchenwald y su experiencia militante en el PCE: la dura experiencia del nazismo y el comunismo vivida en sus carnes. Sus ideas son complejas al respecto, pero pueden simplificarse en el estupor ante la brutalidad del fascismo, la afirmación del fracaso histórico de la tradición comunista surgida de Octubre, las concomitancias entre ambas tradiciones y la restimación de una razón democrática abstracta que se irá moviendo entre cierto izquierdismo de influencia libertaria, la socialdemocracia y el liberalismo. En ese marco general son lugares comunes en su pensamiento la reflexión sobre la alienación de las vidas puestas al servicio de un ideal abstracto y el desgarro y la degradación más concretos de la experiencia militante en los partidos comunistas que dicen deberse a él.

Estas ideas están ya en sus obras del exilio El largo viaje, El desvanecimiento, La segunda muerte de Ramón Mercader ${ }^{29}$ y, por supuesto, en la que, publicada sin embargo en 1977, puede ser considerada una obra del exilio, Autobiografía de Federico Sánchez ${ }^{30}$, el principal pseudónimo,

\footnotetext{
28 Sobre la militancia comunista de Semprún: Nieto, 2014.

29 Semprún, 1963, 1967 y 1969, respectivamente.

30 Semprún, 1977.
} 
como es sabido, que empleaba en la clandestinidad cuando militaba en el PCE. Se trata una obra intensa, lúcida, rica, cargada de errores factuales, resentida y corrosiva contra el PCE, que fue publicada en el año crucial de su legalización y concurrencia a las primeras elecciones, que fue galardonada con el premio Planeta y que en apenas unos meses vendió más de 100000 ejemplares; en otro ejemplo de cómo el exilio, sus figuras y sus escritos estuvieron presentes a la muerte de Franco para ajustar cuentas con el propio exilio y para condicionar el proceso de transición a la democracia. En Autobiografía de Federico Sánchez son frecuentes los análisis penetrantes acerca de la alienación militante: «Una de las características del estalinismo ideológico, consiste, precisamente, en la interiorización autorrepresiva de todos los tópicos colectivos del ególatra supremo» ${ }^{31}$. También las asimilaciones más recurrentes entre fascismo y estalinismo: «Los fascistas tienen: como los estalinistas digo yo ahora: una concepción metafísica y policiaca de la historia» ${ }^{32}$. Y una crítica demoledora, ácida y paródica de la política del PCE y de sus principales dirigentes: «Carrillo encarna la tradición mitológica: la heroica sangre estéril de esa tradición: los sangrientos secretos miserables y las astucias de la razón histórica: el pragmatismo como hilo rojo del ayer al mañana: Ramón [Tamames] encarna las nuevas fuerzas de la cultura: la tecnoburocracia sonriente pero autoritaria del futuro Estado: junto a ellos dos y para que se produzca la santísima fórmula trinitaria bastaría con poner en la cúspide del partido a algún cristiano: algo izquierdista y profético en la medida de lo posible» ${ }^{33}$. Ahora veremos qué línea política y desarrollo estratégico parodiaba Semprún con estas palabras.

\section{Nuevos enfoques y viejas maneras}

Después de la aprobación de la Política de Reconciliación Nacional y hasta poco después de la crisis del 64, el PCE atravesó una fase ingrata, caracterizada por el desarrollo de acciones resistenciales en el estrecho mundo de la clandestinidad y por el lanzamiento esporádico de grandes convocatorias huelguísticas que estuvieron muy lejos de amenazar la estabilidad del régimen. En la década de los sesenta los militantes comu-

\footnotetext{
${ }^{31}$ Semprún, 1977, p. 24.

32 Semprún, 1977, p. 38.

33 Semprún, 1977, p. 40.
} 
nistas pasaron de las penumbras de la clandestinidad a constituirse en la vanguardia de amplios movimientos sociales, gracias al acompasamiento de su práctica política a los cambios que trajo consigo el desarrollismo. El impulso a las Comisiones Obreras en el mundo del trabajo, la creación de sindicatos democráticos en la universidad, la implicación en el movimiento vecinal, la atracción de profesionales e intelectuales y la apertura hacia los sectores progresistas del Catolicismo le convirtieron en el partido político más importante del antifranquismo. Este crecimiento fue resultado de una compleja relación entre la organización del interior y la del exilio. Si bien era la dirección en el exilio la que marcaban la orientación estratégica del partido y fiscalizaba en la medida de sus posibilidades las tareas de las organizaciones del interior, estas impusieron una importante autonomía y creatividad a la hora de llevarla a cabo ${ }^{34}$.

Esta orientación estratégica fue esbozada en los escritos de los principales dirigentes del partido, a veces con interés analítico y propositivo, otras por puro afán propagandístico. A medida que fue siendo objeto de variaciones o diferentes desarrollos tácticos volvió a requerir para su fundamentación de nuevos textos. A veces se trató de obras monográficas, otras de conferencias, informes y estudios sectoriales compilados a posteriori. Este fue el caso, por ejemplo, de los documentos e intervenciones compilados en varios libros publicados a lo largo de los años sesenta por Santiago Carrillo. En ellos se perciben también las aportaciones de algunos dirigentes de mayor talla intelectual de la dirección, particularmente de Manuel Azcárate, sin perjuicio de la propia autoría de Santiago Carrillo, que siempre fue proclive a escribir de su puño y letra. Los textos de Carrillo ponían de manifiesto buena parte de los rasgos de su personalidad política. Se trataba de un dirigente inteligente, pero con mayor capacidad táctica que estratégica; se trataba de un dirigente atento y abierto a algunos de los nuevos enfoques del mejor marxismo de la época, pero siempre propenso a hacerlos encajar en el marco categorial y con las formas propias de la tradición dogmática en que se había formado; se trataba de un dirigente con una considerable formación cultural autodidáctica, pero con las lagunas propias de quien no había pasado por la universidad y no había disfrutado del tiempo suficiente para formarse bien al margen de ella; y se trataba de un diri-

34 Varias síntesis de este proceso en Pala, 2011; Treglia, 2012; Molinero e Ysás, 2017, pp. 17-64. 
gente que, al tiempo que recelaba del mundo intelectual de su propia tradición, se creía con capacidad para reemplazarlo a la hora de fundamentar teóricamente la línea política del partido ${ }^{35}$. Entre los libros de los sesenta que responden a estas motivaciones, capacidades y talantes están Después de Franco, ¿qué? (1965), Nuevos enfoques a problemas de hoy (1967) o Más problemas actuales del socialismo (1969).

En Nuevos enfoques a problemas de hoy Carrillo hacía una apuesta decidida por el potente movimiento de las Comisiones Obreras, que, sin perjuicio de su desarrollo autónomo y de la implicación en él de otros grupos políticos, venía siendo impulsado sobre todo por el Partido Comunista. El PCE estaba contribuyendo a dar forma a un nuevo instrumento de autodefensa de los trabajadores que lo fuera a la vez de oposición a la dictadura, cuyos perfiles eran más propios de un movimiento (que luego se autodefiniría como sociopolítico) que de los sindicatos conocidos hasta entonces en España y buena parte de Europa, incluidos aquellos como la CGT francesa o la CGIL italiana, tan influidos por los respectivos partidos comunistas ${ }^{36}$. Consciente de esta peculiaridad y a fin de minimizar la frecuente acusación de dirigismo del PCE sobre una Comisiones Obreras que en gran medida dirigía, Carrillo reflexionaba sobre la necesidad de unas nuevas relaciones entre partido y movimiento: «la defensa de la unidad va ligada al carácter sin partido y democrático de las Comisiones. Todos estamos interesados en rechazar cualquier intento de llevar a ellas las querellas partiditas y de convertirlas en un apéndice de los partidos, incluso de los partidos de oposición ${ }^{37}$.

El movimiento de las CCOO fue pensado igualmente para aprovechar las vías de representación corporativa y negociación colectiva abiertas por el Régimen. De ahí que Carrillo insistiera en «conservar a toda costa las posiciones legales conquistadas ${ }^{38}$. No obstante, pese a los matices y sus mayores niveles de concreción, el PCE siguió propugnado la idea de una gran huelga general como palanca para el derribo de la dictadura. En palabras del propio Carrillo «sólo la marcha hacia la huelga nacional puede determinar la liquidación de la dictadura ${ }^{39}$.

35 Véanse los trabajos de Souto, Hernández, Erice, Andrade y Gálvez en el dossier sobre la figura de Carrillo en Tiempo Presente, 2014.

36 Vega, 2009 y Treglia, 2012.

37 Carrillo, 1967, p. 59.

38 Carrillo, 1967, p. 66.

39 Carrillo, 1967, p. 89. 
Estos trabajos prestaban una atención importante a los cambios producidos en la composición de clase, en concreto a lo que Carrillo llamaba el «deshielo de la burguesía media». Con ello se refería al surgimiento de una nueva generación procedente de este extracto social que - al no haber vivido los dramas de las grandes guerras del siglo XX, al haber viajado y cursado estudios y al haber respirado los nuevos aires contestatarios de la época - estaba cortando el cordón umbilical ideológico con sus padres y, por ende, con su clase. No obstante, el acierto que suponía poner el acento en estos fenómenos se veía minimizado cuando se los reducía a una nueva expresión de otros fenómenos clásicos y se trataba de encajarlos en los marcos categoriales de siempre, que tampoco se manejaban con demasiado rigor. Así, para Santiago Carrillo estas «formas de lucha generacional» no eran «más que el reflejo de otra lucha más profunda, el reflejo de la lucha de clases, de la oposición de las fuerzas progresistas y las fuerzas reaccionarias y conservadoras de la sociedad ${ }^{40}$. Se hablaba de la nueva lucha generacional como mera derivación de la lucha de clases de siempre, pero esta se reducía a una superficial confrontación ideológica.

En cualquier caso, estas reflexiones condujeron a una propuesta novedosa del PCE que con el tiempo adquirió mayores cotas de desarrollo teórico: la propuesta de «alianza de las fuerzas del trabajo y la cultura». Según los análisis del PCE, la progresiva masificación y degradación laboral de los técnicos, profesionales e intelectuales en el nuevo modelo de desarrollo capitalista de postguerra - lo que al principio denominarán como capitalismo monopolista de Estado - les empujaba a una mayor proximidad objetiva a la clase obrera. Al mismo tiempo, su formación y sintonía con los valores democráticos y sociales, que se iban abriendo espacio en sus lugares naturales de educación y ocio, les dotaba de una subjetividad proclive al cambio social ${ }^{41}$. Estos análisis del PCE descansaban sobre todo en la influencia que en los sesenta empezó a tener la obra del intelectual comunista italiano Antonio Gramsci, en concreto su concepción más compleja acerca de la articulación social de los sujetos de cambio en lo que vino a llamar «Bloque histórico», así como del papel en él de los técnicos e intelectuales. Estas reflexiones elaboradas por Gramsci en cárcel en los años 20 y 30 fueron luego refinadas con la incorporación de nuevos análisis sobre el impacto de los avances científico-técnicos en el modelo

\footnotetext{
40 Carrillo, 1967, p. 108.

41 Carrillo, 1967, pp. 168-172
} 
productivo y los cambios que ello generó en la estructura de clase, como los elaborados por Radovan Richta. En medio había tenido lugar el estallido social del 68, en el que, además del protagonismo obrero pocas veces subrayado en las crónicas más periodísticas y estereotípicas de la época, emergía una nueva generación de estudiantes y profesionales jóvenes que se habían criado y educado en los años de crecimiento económico ${ }^{42}$.

El desarrollo de esta lógica aperturista se extendió al mundo católico, estimulada por el surgimiento de un cristianismo de base a fin a la causa de los trabajadores (JOC, HOAC) y por la apertura recíproca de algunos sectores de la Iglesia sacudidos por los nuevos aires del Concilio Vaticano Segundo. Los análisis acerca de los cambios en el catolicismo y las propuestas de conexión con sus nuevas expresiones progresistas fueron frecuentes en los documentos oficiales del PCE. No obstante, merecieron un desarrollo más profundo de la mano de una de las figuras de mayor talla intelectual en la dirección del partido en el exilio durante los sesenta y setenta, aquel que vino a refinar teóricamente muchas de las iniciativas más intuitivas de Santiago Carrillo, el ya citado Manuel Azcárate, la persona nombrada además por Carrillo como interlocutor del partido con el mundo católico. El movimiento de aproximación entre cristianos y marxista no fue exclusivo de España. A un lado y al otro del telón de acero surgieron multitud de iniciativas al respecto, como los encuentros entre cristianos y marxistas de Salzburgo en 1965, de Herreninsen (República Federal Alemana) en 1966 y de Marianzske-Lazne (Checoslovaquia) en 1967, en el que intervino el propio Manuel Azcárate. Las reflexiones de este intelectual comunista en el exilio, hijo del Diplomático Pablo de Azcárate, pueden verse en el texto «Realidades españolas en el diálogo cristiano marxista» publicado ese año de 1967 en Nuestra Bandera, la revista teórica del PCE. En el artículo se constataba que la religión -instrumento tradicional para el adocenamiento y la sumisión de los sectores populares, paliativo simbólico de los males sociales por la vía de la promesa escatológica y la resignación mundana, opio adormecedor del pueblo- estaba siendo objeto de un uso emancipador aquí en la tierra por parte de muchos creyentes. Azcárate subrayaba además la atracción que importantes intelectuales católicos tenían hacia la teoría económica, social y cultural marxista; que el movimiento obrero estaba emergiendo gracias también al papel de organizaciones cristianas como la JOC, la HOAC, AST y USO,

42 Eley, 2003, pp. 339-362 
hasta el punto de que muchos de quienes se habían formado dentro de sus filas habían dado el salto hacia CCOO; y que, en última instancia, las diferencias filosóficas innegables e irreductibles entre cristianos y marxistas no eran óbice para, a partir de un diálogo proclive al entendimiento y una práctica en pos de objetivos comunes, cristianos y marxistas pudieran llegar a compartir un mismo proyecto político y de sociedad ${ }^{43}$.

En paralelo a esta evolución la dirección del partido y sus intelectuales fueron ampliando sus análisis sobre los países del socialismo real y en concreto sobre la Unión Soviética. Al principio estuvieron de sobra condicionados al sentido de obediencia debida a la «gran patria del socialismo», a la dependencia material que algunos de los dirigentes y muchos de los exiliados del partido (y el partido en general) tenían de Moscú ${ }^{44}$ y a la lógica dicotómica de la Guerra Fría, por la cual se cerraban filas en torno a la URSS para evitar que cualquier reflexión no muy entusiasta sobre ella pudiera ser aprovechada por el enemigo americano. Cuando esta dependencia material se fue aliviando, cuando el eje de la dirección del partido se desplazó a Francia, cuando penetró en el PCE la influencia del Partido Comunista Francés y especialmente del Italiano, cuando las pautas de pensamiento de muchos intelectuales y dirigentes del exilio se fueron adecuando a los parámetros políticos y culturales de sociedades de acogida en las que leían, vivían y escribían, esa obediencia fue cediendo a una actitud primero distante y finalmente crítica con algunos episodios más o menos tensos, como la condena a la invasión de Checoslovaquia por parte de las tropas de Varsovia para reprimir la Primavera de Praga ${ }^{45}$.

Los análisis sobre la URSS se centraron en su condición de gran potencia mundial en la geopolítica variable de la Guerra Fría, en su papel sobre el conjunto del movimiento comunista y, finalmente, en su consideración como modelo o no de socialismo. El alineamiento del PCE y sus intelectuales con la URSS fue inequívoco en los primeros momentos de la Guerra Fría, pese a que en sus declaraciones y escritos públicos los dirigentes e intelectuales españoles evitaran verbalizarlo en los momentos de tensión y tendieran a poner el acento en los de distensión, normalmente atribuidos a la voluntad de entendimiento procedente de Moscú. Progresivamente se centraron en subrayar y respaldar las iniciativas de aproximación procedente de ambos bandos y en celebrar el surgimiento de terceras

\footnotetext{
43 Azcárate, 1967.

44 Véase al respecto el reciente libro de Eiroa, 2018.

45 Pala y Nencioni, 2008.
} 
vías y no alineados. Finalmente, se llegaron a denunciar en algunos casos las actitudes belicistas de la URSS.

Sobre lo segundo, el PCE y sus intelectuales secundaron acríticamente la disolución de la Komintern en 1943, la creación de la Kominform en 1947 (una reactualización más laxa de aquella tras el incremento de la tensión bipolar) y la disolución de esta en 1956 a instancias de Kruschev. La actitud del PCE en las siguientes conferencias mundiales de partidos comunistas consistió en respaldar al principio las pretensiones no confesas de dirigismo del PCUS, para, progresivamente, ir acercándose, normalmente a rebufo, a las tesis del policentrismo esbozadas por Togliatti y sus sucesores al frente del PCI, que finalmente condujeron a la propuesta de desarrollo autónomo de vías nacionales al socialismo fuera del tutelaje soviético ${ }^{46}$.

Los comunistas españoles nunca llegaron a tomar el sistema socialista de la URSS como modelo o referente para España, por más que la propaganda enemiga del régimen o adversaria del exilio se afanara en repetirlo. El modelo de socialismo para España se fue identificando progresivamente, como se ha visto, con la institucionalidad democrática occidental. Se evitaba considerar el sistema soviético en su totalidad para no incurrir en contradicciones. Normalmente, los dirigentes e intelectuales comunistas españoles se referían a desarrollos parciales y concretos del sistema soviético que se consideraban positivos, y recurrían a una fuerte contextualización histórica de pretensiones más o menos absolutorias (el peso del atraso secular en Rusia, el boicot sufrido desde los primeros momentos por parte de las potencias capitalistas, la necesidad de defenderse de la presión americana) para explicar aquellos eminentemente autoritarios. Con el paso del tiempo el tono crítico fue aumentando, ya no solo a propósito del dirigismo soviético, sino del tipo de socialismo construido en Rusia.

Estas consideraciones críticas estuvieron marcadas por la propia evolución ideológica de los dirigentes e intelectuales comunistas españoles del exilio, pero también estuvieron muy condicionadas por la sentida necesidad de fortalecer su credibilidad democrática ante una sociedad como la española que, tras la experiencia de la guerra y la prolongada dictadura, añoraba la democracia. Igualmente la crítica a la URSS se vio estimulada por el intento de otras fuerzas de la oposición

46 Sánchez Rodríguez, 2004, pp. 145-154 y 171-173. 
de desacreditarle como partido democrático asociándolo al Estado soviético, una presión ante la cual al final también terminó cediendo en los términos que estas le demandaban.

El distanciamiento del PCE con respecto al PCUS y la URSS en el exilio tiene tres textos progresivamente críticos. Uno es un artículo de Santiago Álvarez publicado en Nuestra Bandera, en el que recogía algunas de las reflexiones más o menos críticas vertidas en el encuentro preparatorio de Budapest de la Conferencia de Partidos Comunistas de Moscú que se celebraría un año después en $1969^{47}$. Otro es la intervención de Santiago Carrillo en dicha conferencia, donde austriacos, británicos, italianos y españoles fueron particularmente duros con la intervención en Checoslovaquia y abogaron por la descentralización del movimiento comunista, la autonomía de cada partido y la libertad a la hora de cuestionar las políticas de los países socialistas. Santiago Carrillo lo dijo allí públicamente: «Adoptemos una actitud crítica cuando consideremos que se produce un fenómeno negativo en un país socialista [...] Así ha ocurrido con motivo de la acción emprendida en Checoslovaquia el año pasado por cinco países del Pacto de Varsovia ${ }^{48}$. El texto más duro con la URSS fue el informe de Manuel Azcárate como responsable internacional del PCE al Comité Central publicado en 1973. En él explicaba la rivalidad chinosoviética en términos de intereses imperiales contrapuestos y denunciaba como males del modelo soviético la burocratización, la desideologización y la fusión del partido y el Estado ${ }^{49}$

Todos estos cambios, tendencias, teorizaciones y nuevos enfoques terminarían cristalizando ya en la transición en lo que terminó llamándose el eurocomunismo.

\section{Intelectuales comunistas en la periferia: Wenceslao Roces y Adolfo Sánchez Vázquez}

Lejos del núcleo dirigente del PCE en el exilio, lejos también de muchos de sus espacios orgánicos de debate y producción teórica y lejos geográficamente de donde con el paso del tiempo se fueron ubicando uno y otros (Europa y, especialmente, Francia) hubo otros comunistas que de-

\footnotetext{
47 Álvarez, 1968.

48 Carrillo, 1969, p. 120.

49 Azcárate, 1973.
} 
sarrollaron una importante carrera intelectual. Nos referimos, por ejemplo, a Wenceslao Roces y, sobre todo, a Adolfo Sánchez Vázquez, los dos exiliados en México. Ambos autores deben ser considerados, sin duda, referentes fundamentales del pensamiento español en el exilio, pero además de ello, o más allá de ello, Wenceslao Roces y Adolfo Sánchez Vázquez se convirtieron en grandes referentes del pensamiento y la política en México y buena parte de América Latina, donde a la postre tuvieron mayor ascendencia y recibieron mayor reconocimiento al obtenido en la España postfranquista. En este sentido, tanto Roces como Sánchez Vázquez deben considerarse también intelectuales latinoamericanos en general y mexicanos en particular.

Al salir al exilio Wenceslao Roces era probablemente el intelectual comunista español de más dilatada carrera académica. Se había licenciado en Derecho por la Universidad de Oviedo, se había doctorado en la de Madrid, había disfrutado de una beca en Alemania y de regreso había ganado la Cátedra de Instituciones de Derecho Romano en la Universidad de Salamanca. En la Guerra Civil desempeñó importantes tareas gubernamentales, como la protección de las obras del Museo del Prado.

Después de la derrota en la Guerra Civil se instaló definitivamente en México, tras un breve paso por Chile y Cuba. Como profesor de la Universidad Nacional Autónoma de México, en la que desempeñó la mayor parte de su carrera, impartió primero la Cátedra de Derecho Romano en la Facultad de Derecho y dirigió posteriormente el Seminario de Historia Antigua en la Facultad de Filosofía y Letras, donde también impartió cursos de filosofía marxista. La UNAM le nombró profesor emérito en 1969.

Tanto o más reconocida e intensa fue su labor como traductor, especialmente para las editoriales Grijalbo y Fondo de Cultura Económica, en la cual creó y dirigió además la colección Grandes Obras de la Historia. Entre la infinidad de autores que tradujo al castellano cabe citar a Hegel, Alexandre Koyré, Wilhelm Dilthey, Ernst Cassirer, Hans Kelsen o Ernst Bloch; a clásicos del marxismo como Lafargue o Liebknecht; y, por supuesto, a Engels y el propio Marx. No en vano fue el traductor al castellano de una de las ediciones del Capital más leídas en el mundo hispanohablante.

Su producción política puede rastrearse en la infinidad de prólogos y estudios introductorios a las muchas obras que tradujo, así como en las conferencias magistrales que impartió en universidades, ateneos y actos culturales de partido, como la pronunciada en 1945 bajo el título El marxismo, humanismo de nuestra época, la impartida para la delegación del 
PCE en México con el título La Cultura, los Intelectuales y el Partido comunista o la pronunciada en 1970 con motivo del centenario del nacimiento de Lenin en la UNAM, Lenin o la fecundidad de las ideas. También fue frecuente su participación en las revistas teóricas del PCE o de su entorno cultural, como por ejemplo Nuestra Bandera o Realidad: revista de cultura y política. Antes de que estas revistas se enriquecieran con las aportaciones de las nuevas generaciones formadas en el interior (aunque con fuertes vínculos con el exterior), como Manuel Sacristán, Manuel Ballestero, Armando López Salinas, Román Gubern o Carlos Castilla del Pino, autores como Wenceslao Roces sostuvieron su pulso teórico. Posteriormente, en diálogo con esta nueva generación, Roces contribuyó también al enriquecimiento y renovación de estas publicaciones. De sus muchos artículos en ellas puede sacarse a colación «Universidad y Humanismo» (1967), donde Roces aboga por una concepción antiautoritaria en tres esferas de actividad que tan bien conocía, que puso en relación y que estaban asfixiadas por formas de culto a la personalidad: la gestión pública, la militancia política y la docencia universitaria. La crítica la expresaba de la siguiente forma:

El culto a la personalidad del profesor, como a la del gobernante o del gran hombre, se alimenta parasitariamente del desprecio a la personalidad de los demás, alumnos, gobernados o fieles [...] Ese culto es, en rigor, en quien lo acepta y en quien lo tributa, el mayor de los agravios a la verdadera personalidad, el culto a la despersonificación. La personalidad auténtica sólo se forma y se afirma entre iguales, entre otras personalidades, respetándolas y ayudando a crearlas; no se da nunca entre enanos o adoradores. Estos, a la postre, acaban rebelándose contra la enajenación, y ya sabemos - la historia de ayer como la de hoy nos lo enseña- que no hay peores rebeliones que las de los resentidos, carentes de propia conciencia y personalidad. (Roces, 1967: 21 y 22).

Una de las trayectorias intelectuales más fértiles y novedosas del exilio comunista fue la de Adolfo Sánchez Vázquez. Su magisterio y compromiso durante su exilio en México dejaron una honda influencia en el país norteamericano y en buena parte de América latina. Pese a ello Adolfo Sánchez Vázquez nunca formó parte del reducido elenco de pensadores del exilio que la democracia española del 78 incluyó en su panteón. Ello se debió, probablemente, al hecho de que Sánchez Vázquez decidiera no regresar a España tras el fin de la dictadura y a que durante los años setenta, ochenta y noventa siguiera defendiendo un marxismo crítico 
y heterodoxo que no encajaba en el canon social liberal que en la transición y en la democracia consolidaron, entre otros, muchos de quienes previamente habían militado en un marxismo generalmente dogmático y esclerotizado. Tardíamente su obra y figura empezaron a recibir reconocimiento también en España más allá de los reducidos ambientes de la izquierda alternativa, en los que no siempre lo tuvo.

Adolfo Sánchez Vázquez se crio en Málaga, donde estudió Magisterio e inició su toma de conciencia política. Más tarde, en 1935, fue seleccionado para estudiar en la Facultad de Filosofía y Letras de Madrid, donde asistió a las clases de los grandes filósofos españoles de la época, frecuentó tertulias literarias, participó en asociaciones estudiantiles de la izquierda y terminó engrosando en 1936 las filas de la Juventud Socialista Unificada. Durante la Guerra Civil realizó importantes tareas con cargo a esta organización como responsable del periódico Ahora o Comisario político en el frente.

En junio de 1939 Adolfo Sánchez Vázquez llegó a México. Allí rehízo su vida e inició una ascendente carrera intelectual y universitaria, primero como profesor en Morelia y luego en la UNAM, donde terminó siendo investido profesor emérito. Después de una primera etapa sobre todo literaria su producción fue girando hacia el campo de la filosofía, en concreto al ámbito de la ética, la teoría estética y la filosofía política. En su texto de cariz autobiográfico, «Mi obra filosófica», lo explicaba del siguiente modo: «Una truncada práctica literaria y, más precisamente, poética, me llevó a problematizar cuestiones estéticas, y una práctica política me condujo a la necesidad de esclarecerme cuestiones fundamentales de ella y, de esta manera, casi sin proponérmelo, me encontré en el terreno de la filosofía ${ }^{50}$. Esa preocupación estética le llevó a la escritura de Las ideas estéticas de Marx. Ensayos de estética y marxismo (1965), y de la Antología crítica Estética y Marxismo (1970). Esa actividad política, extrema durante la guerra y orientada luego a la reconstrucción del PCE en México, le llevaron a reflexionar intensamente sobre la noción praxis, a diferencia de otros filósofos también marxistas formados exclusivamente en la academia en la época de la estabilización de los frentes geopolíticos de los años cincuenta, más dados al estudios de las grandes estructuras sociales y económicas. A la fundamentación ética de esta praxis dedicó libros como Ética (1969).

50 Sánchez Vazquez, 1985, p. 7. 
Dentro de su obra más estrictamente política, pero profundamente filosófica, destacan los ensayos Del socialismo científico al socialismo utópico (1975) y, sobre todo, Filosofía de la Praxis (1967). En el primero se pone particularmente de manifiesto un empeño que ocupó la mayor parte de su quehacer intelectual: el de reivindicar la importancia en la evolución del pensamiento de una tradición tan rica y compleja como la del marxismo, cuya virtualidad para el presente requeriría de su historización crítica. Adolfo Sánchez Vázquez reivindicaba la necesidad de interpretar la producción marxista desde parámetros marxistas, es decir, la necesidad de concebirla como un producto cultural de época cuya actualización necesitaba de una lectura crítica y autocrítica que evitase su inclinación al esquematismo y sus frecuentes versiones dogmáticas. El sugerente título - una inversión del título del famoso escrito de Engels Del socialismo utópico al socialismo científico - anticipaba la idea de una regresión del marxismo, por la vía de su idealización, a planteamientos anteriores a los de su fundamentación materialista por Marx y Engels ${ }^{51}$.

Filosofía de la Praxis es una de sus obras más destacadas, una contribución notable y novedosa al campo general del marxismo. La obra, resultado de su investigación doctoral, fue publicada en 1967 y se constituyó en un libro de referencia en el contexto mexicano y latinoamericano del 68, en la medida que, después de la primacía de una tradición de pensamiento marxista que enfatizaba el peso avasallador de las grandes estructuras económicas y sociales, el libro de Sánchez Vázquez reivindicaba las posibilidades de trasformación de una práctica política teóricamente fundamentada y de un pensamiento anclado en la propia práctica política. Esta reivindicación la hacía a partir de una amplia revisión de la tradición filosófica en general y de la marxista en particular, dentro de la cual reconocía el carácter pionero de Antonio Gramsci, que según Sánchez Vázquez hacía de la praxis el «principio unificador de todas las partes del marxismo y categoría filosófica central $»^{52}$.

La filosofía de la praxis de Sánchez Vázquez pretendía articular el conocimiento y la crítica de la realidad con un proyecto para su transformación radical. Lo que en opinión de Sánchez Vázquez caracterizaba a la filosofía de la praxis no era tanto su reflexión sobre las prácticas emancipadoras de los hombres y mujeres, como el hecho de que esa reflexión se

51 Sánchez Vázquez, 1975.

52 Sánchez Vazquez, 1980, p. 50 (primera edición 1967) 
concibiera a sí misma formando parte de dicho proceso de emancipación. Desde esta perspectiva, tal forma de filosofar se concebía a sí misma fundada, nutrida e impulsada por la praxis, al tiempo que esta forma de filosofar se integraba dentro de la praxis como un momento necesario para incrementar su potencia y perfilar su orientación.

La filosofía de la praxis de Sánchez Vázquez es también una toma de conciencia de la práctica política sobre sí misma y una reflexión sobre ella orientada a su fortalecimiento; no es una filosofía sobre la praxis, sino la praxis tomando conciencia de sí misma en la perspectiva de elevar su propia racionalidad y potencial transformador. Para Sánchez Vázquez el marxismo crítico, desprovisto de sus adherencias dogmáticas y en sus expresiones más auténticas, era la filosofía de la praxis de su época:

Como Filosofía de la praxis, el marxismo es la conciencia filosófica de la actividad práctica humana que transforma el mundo. Como teoría no solo se halla en relación con la praxis - revela su fundamento, condiciones y objetivos - sino que se sabe a sí misma en dicha relación y, por ello, es una guía de la acción ${ }^{53}$.

Como es sabido Adolfo Sánchez Vázquez no se asentó nunca definitivamente en España tras la muerte de Franco, sino que siguió con su vida personal y profesional en México. Tampoco se integró especialmente en la vida cultural e intelectual española, ni siquiera en la de la izquierda académica, ni demasiado en la promovida por el propio PCE. El caso de Adolfo Sánchez Vázquez es representativo de la limitada y muy selectiva inclusión del exilio en la cultura postfranquista. El exilio, en su integridad y complejidad, ha supuesto una presencia muchas veces incómoda e increpante para la cultura de Estado y el sistema político construidos en la transición y desarrollados en las décadas siguientes. A esa escala e intensidad, el exilio republicano no podía ser ni asimilado ni cooptado, en la medida que portaba el legado cultural y político de un régimen, el de Segunda República, tan distinto en sus formas, contenidos y aspiraciones al de la Constitución de 1978. También porque con él iban los múltiples proyectos, aspiraciones e ideaciones producidos, sentidos y defendidos durante tantos años de exilio; algunos de ellos, como aquí se ha visto, en consonancia, más o menos forzada, con el curso posterior de los acontecimientos democratizadores y el espíritu de la época postfranquista; otros,

53 Sánchez Vazquez, 1980, p. 176 (primera edición 1967) 
como sería el caso de Adolfo Sánchez, contrarios o ajenos a una cosa u otra. A la postre varios de estos intelectuales y comunistas del exilio han sido, bien coherentemente, bien instrumentalización mediante, integrados al canon cultural y político de la democracia en los ochenta y noventa ${ }^{54}$. Fernando Claudín y Jorge Semprún, en gran medida, y Manuel Azcárate o Santiago Carrillo, en otro sentido, han sido incorporados al acervo de la práctica y el pensamiento políticos reconocidos en la democracia. Exiliados todavía, en cierta medida, de ese canon y ese acervo quedan otros intelectuales comunistas que dejaron un rico legado a recuperar.

\section{Bibliografía}

Álvarez, Santiago, «De encuentro de Budapest a la Conferencia de Moscú», Nuestra Bandera, 58, 1968.

ANDERSOn, Perry, Consideraciones sobre el marxismo occidental, Madrid, Siglo XXI, 2015.

ANDRADE, Juan. El PCE y el PSOE en (la) transición. Madrid: Siglo XXI, 2015.

ARISTÓTELES, Política, Madrid, Alianza, 1999.

AzCÁRATE, Manuel, «Realidades españolas en el diálogo cristiano marxista», Nuestra Bandera, 1967.

AzCÁRATE, Manuel, «Sobre la política internacional del PCE. Informe al Comité Central», Nuestra Bandera, n. ${ }^{\circ}$ 72, 1973.

BALIBREA, Mari Paz y FABER, Sebastian, «Hacia otra historiografía cultural del exilio republicano español. Introducción a modo de manifiesto» en BALIBREA, Mari Paz (coord.) Líneas de fuga. Hacia otra historiografía cultural del exilio, Madrid: Siglo XXI, 2017.

Bolloten, Burnett, La Guerra Civil Española: revolución y contrarrevolución, Madrid, Alianza, 1989.

Bolloten, Burnett, The grand camouflage: the communist conspiracy in the Spanish civil war, London, Hollis \& Carter, 1961.

BOURDIEU, Pierre, Intelectuales, política y poder, Madrid, Claves, 2012.

Carrillo, Santiago, Después de Franco, ¿qué?, París, Editions Sociales, 1965.

Carrillo, Santiago, Discurso Pronunciado en la Conferencia de los Partidos comunistas y obreros de Moscú, Junio de 1969.

Carrillo, Santiago, Más problemas actuales del socialismo. Discurso pronunciado en la Conferencia de Partidos Comunistas de Moscú, París, Librairie du Globe, 1969.

${ }^{54}$ Balbrea y Faber, 2017, pp. 16-19. 
CARRILlo, Santiago, Memoria de la transición (la vida política española y el $P C E)$, Barcelona, Grijalbo, 1983.

CARrillo, Santiago, Nuevos enfoques a problemas de hoy, París, Editions Sociales, 1967.

Castro Delgado, Enrique, Hombres made in Moscú, Editorial Caralt, Barcelona, 1963.

Castro Delgado, Enrique, La vida interna de la Komintern: Cómo perdí la fe en Moscú, Madrid, Epesa, 1950.

Claudín, Fernando, Crisis del movimiento Comunista, París, Ruedo Ibérico, 1970.

Claudín, Fernando, Documentos de una divergencia comunista, Barcelona, El Viejo Topo, 1978.

Del Rosal, Amaro, Los congresos obreros internacionales en el siglo XIX: de la joven Europa a la Segunda Internacional, México: Grilabo, 1958

Del Rosal, Amaro, Los congresos obreros internacionales en el siglo XX: de 1900 a 1950, México, Grijalbo, 1963.

DOMÈNECH, Antoni, El eclipse de la fraternidad. Una revisión republicana de la tradición socialista, Barcelona, Crítica, 2004.

DuARTE, Ángel, El republicanismo. Una pasión política, Madrid, Cátedra, 2013.

EIROA, Matilde, Españoles tras el telón de acero. El exilio republicano y comunista en la Europa Socialista, Madrid, Marcial Pons, 2018.

ELEY, Geoff., Un mundo que ganar. Historia de la izquierda en Europa. 18502000, Barcelona, Crítica, 2002.

ERICE, Francisco, «Los condicionamientos del «giro táctico» en 1956: el Contexto de la Política de Reconciliación Nacional», Papeles de la FIM, 24, 2006.

Esteban Novillo, Rito, Lucha de clases y movimiento obrero, La Habana, Imprenta Nacional de Cuba, 1961.

Esteban Novillo, Rito, Sobre el movimiento obrero de Europa y América, La Habana, Imprenta Nacional de Cuba, 1946.

GLONDYs, Olga, La Guerra Fría cultural y el exilio republicano español. Cuadernos del Congreso por la Libertad de la Cultura (1953-1965), Madrid, CSIC, 2012.

GonZÁlez, Valentín, Comunista en España y antiestalinista en la URSS, México, Guarania,1952.

GonZÁLEZ, Valentín, Vida y muerte en la URSS, Buenos Aires-Bel, 1951.

GRAMSCI, Antonio, Los intelectuales y la organización de la cultura, Buenos Aires, Nueva Visión, 2004.

HANISCH, Carol, Lo personal es político, 1969, consultado en www.autonomiafeminista.cl /

Hernández Sánchez, Fernando, Comunistas sin partido. Jesús Hernández. Ministro en la Guerra Civil, disidente en el exilio, Madrid, Raíces, 2007.

Hernández SÁnchez, Fernando, Guerra o revolución. El Partido Comunista de España en la Guerra Civil, Barcelona, Crítica, 2010. 
HERnÁNDEZ SÁNCHEZ, Fernando, Los años de plomo. La reconstrucción del PCE en el primer franquismo (1939-1953), Barcelona, Crítica, 2015.

HERNÁNDEZ SANDOICA, Elena, Tendencias historiográficas actuales. Escribir historia hoy, Madrid, Akal, 2004.

Hernández, Jesús, Yo fui ministro de Stalin, México D.F., Editorial América, 1953.

JAUME, Lucien, «El pensamiento en acción», Ayer, 53, 2004.

KoSELlECK, Reinhart, Historia de conceptos. Estudios sobre semántica y pragmática del lenguaje político y social, Madrid, Trotta, 2012

Molinero, Carme e Ysás, Pere., De la hegemonía a la autodestrucción. El Partido Comunista de España (1956-1982), Barcelona, Crítica, 2017.

NelKen, Margarita, Las torres del Kremlin, México: Industrial y distribuidora S.A., 1943.

NiETo, Felipe, La aventura comunista de Jorge Semprún: exilio, clandestinidad y ruptura, Madrid, Tusquets, 2014.

Pala, Giaime y Nencioni, Tommaso, El inicio del fin del mito soviético. Los comunistas occidentales ante la Primavera de Praga, Barcelona, Viejo Topo, 2008.

Pala, Giaime, El Psuc: L'antifranquisme $i$ la politica d'aliances a Catalunya (1956-1977), Barcelona, Base, 2011.

PCE, Guerra y revolución en España. 1936-39. Seis Volúmenes, Moscú, Editorial Progreso, 1967.

PCE, Historia del Partido Comunista de España, París, Éditios Sociales, 1960.

Roces, Wenceslao, «Universidad y Humanismo», Realidad, n. ${ }^{\circ}$ 14, 1967

Roces, Wenceslao, El marxismo, humanismo de nuestra época; La Cultura, los Intelectuales y el Partido comunista, Lenin o la fecundidad de las ideas, conferencias consultables en http://www.wenceslaoroces.org/arc/roces/index.htm

SÁnCHEZ RodríGuez, Jesús, Teoría y práctica democrática en el PCE (19561982), Madrid, FIM, 2004.

SÁNCHEZ VÁZQUEZ, Adolfo, «Mi obra filosófica», Anthropos: Boletín de información y documentación, N. ${ }^{\circ}$ 52, 1985.

SÁNCHEZ VÁzQueZ, Adolfo, Del socialismo científico al socialismo utópico, Ediciones Era, 1975

SÁNCHEZ VÁzQUEZ, Adolfo, Ética, México, Grijalbo, 1969.

SÁnChez VÁzQuez, Adolfo, Filosofía de la Praxis, Barcelona, Grijalbo, 1985, primera edición 1967.

SÁNCHEZ VÁzQueZ, Adolfo, Las ideas estéticas de Marx. Ensayos de estética y marxismo, México, 2005, primera edición

Semprún, Jorge, Autobiografía de Federico Sánchez, Barcelona, Planeta, 1977.

SEMPRún, Jorge, El desvanecimiento, Barcelona, Planeta, 1979, primera edición en francés 1967 
SEMPRÚn, Jorge, El largo viaje, Barcelona, Seix Barral,1976, primera edición en francés 1963

SEMPRÚn, Jorge, La segunda muerte de Ramón Mercader, Teimpo Nuevo, 1970.

SERVICE, Robert, The Penguin History of Modern Russia. From the Tsarism to the Twenty-First Century, London, Penguin Books, 2015.

SKINNER, Quentin, Visions of politics, 3 Vols., Cambridge, Cambridge University Press, 2012.

Treglia, Emanuele, Fuera de las catacumbas, La política del PCE y el movimiento obrero, Madrid, Eneida, 2012.

VALVERDE, María José, «La política de Reconciliación Nacional: contenidos y planteamientos», Papeles de la FIM, 24, 2006.

Vega García, Rubén, «Las fuerzas del trabajo. Los comunistas en el movimiento obrero durante el Franquismo», en BUENo, Manuel y GÁlvez, Sergio (ed.), Árbol académico, 2009.

Wolikov, Serge, «¿Qué clase de acontecimiento? Historiografía y actualidad de las investigaciones sobre el Frente Popular», Nuestra Historia. Revista de Historia de la FIM, n. ${ }^{\circ} 1,2016$.

\section{Financiación}

Este trabajo se enmarca en el proyecto financiado por la AEI/FEDER, «La historia de la literatura española y el exilio republicano de 1939» (FFI2017-84768-R).

\section{Datos del autor}

Doctor en Historia Contemporánea y profesor en la Facultad de Formación del Profesorado de la Universidad de Extremadura. Premio al mejor expediente académico de su promoción y Premio extraordinario de Doctorado. Estancias investigación en distintas universidades europeas (London School of Economics), en Estados Unidos (Princeton University) y en América Latina. Autor del libro El PCE y el PSOE en (la) transición, Madrid, Siglo XXI-España, 2012, segunda edición en 2015. Autor, junto a Julio Anguita, del libro Atraco a la memoria, Madrid, AKAL, 2015. Editor y coautor, junto a Fernando Hernández Sánchez, del libro colectivo 1917. La revolución rusa 100 años después, Madrid, AKAL, 1917. Una decena de Artículos publicados en revistas especializadas (Ayer, Tiempo Presente, Historia Social) Director de la colección «Reverso-historia crítica» de la editorial AKAL. 